\title{
Diversity of silver resistance genes in IncH incompatibility group plasmids
}

\author{
Amit Gupta, ${ }^{1} \dagger$ Le T. Phung, ${ }^{1}$ Diane E. Taylor ${ }^{2}$ and Simon Silver ${ }^{1}$ \\ Author for correspondence: Amit Gupta. Tel: +1 630305 1735. Fax: +1 6303052982. \\ e-mail: agupta@uic.edu
}

1 Department of Microbiology and Immunology, University of Illinois, M/C 790, $835 \mathrm{~S}$. Wolcott Ave, Room E-703, Chicago, IL 60612-7344 USA

2 Department of Medical Microbiology and Immunology, University of Alberta, Edmonton T6G 2 H7 Alberta Canada

\begin{abstract}
Silver compounds are used as antimicrobial agents in medicine and bacteria that develop resistance to silver cations $\left(\mathrm{Ag}^{+}\right)$pose problems similar to those of antibiotic-resistant bacteria. The first set of $\mathrm{Ag}^{+}$resistance genes (sil) was from plasmid pMG101, now assigned to the IncHI incompatibility group. Questions of whether sil genes are unique to pMG101 or are more widely found, and whether they are associated with a specific incompatibility group or occur in many plasmid groups and on bacterial chromosomes were addressed. sil genes were identified in five IncH plasmids, but not in plasmids of the IncP incompatibility group. Three sil genes (silP, silR and silE) from these plasmids were PCR-amplified, cloned, sequenced and compared to those of pMG101. Differences of 0-50 nt per kb of sequence were found. Predicted gene products were 0-6\% different in amino acid sequence, but the differences did not alter residues thought to be involved in protein function (see supplementary data at http://mic.sgmjournals.org or http://www.uic.edu/depts/mcmi/individual/gupta/index.htm). For representative IncH plasmid R476b and pMG101 the effects of $\mathrm{Ag}^{+}$exposure on resistance levels were measured by growth. The inducibility of silC, silR and silE gene expression after $\mathrm{Ag}^{+}$exposure was studied by reverse transcriptase (RT)-PCR. Silver resistance increased after $\mathrm{Ag}^{+}$exposure for strains carrying plasmid R476b. silC and silE expression from R476b was inducible after $\mathbf{A g}^{+}$ exposure and was constitutive and high from pMG101. The mRNA levels for the regulatory gene silR was constitutive for both PMG101 and R476b. Close homologues for SiIABC(ORF96)RS from PMG101 are clustered on the chromosomes of Escherichia coli strains K-12 and 0157:H7, without contiguous silP and silE homologues. Insertion deletions of the $E$. coli K-12 chromosomal homologues for silA and silP gave $\mathrm{Ag}^{+}$hypersensitivity for growth. The silA homologue knockout was complemented back to wild-type resistance by the same gene cloned on a plasmid. Homologues of sil genes have also been identified on other enterobacterial genomes.
\end{abstract}

Keywords: IncH plasmids, E. coli chromosome, plasmid incompatibility group

\section{INTRODUCTION}

Some metal cations $\left(\mathrm{Zn}^{2+}, \mathrm{Cu}^{2+}, \mathrm{Co}^{2+}\right.$ and $\left.\mathrm{Ni}^{2+}\right)$ are essential trace nutrients for living cells and function in enzymic reactions. Heavy metal cations $\left(\mathrm{Ag}^{+}, \mathrm{Cd}^{2+}\right.$, $\mathrm{Pb}^{2+}$ and $\mathrm{Hg}^{2+}$ ) are non-essential and toxic. Metal salts

\footnotetext{
† Present address: ONDEO-Nalco Company, One Nalco Center, Naperville, IL 605 3, USA.

The GenBank accession numbers for the sequences reported in this paper are AY009372-AY009396.
}

and compounds are often used as antimicrobial agents in medicine and as biocides in hospitals and other human settings.

Silver compounds and products are increasingly common as microbicidal agents in hygiene, agriculture and industry, in addition to clinical uses (reviewed by Gupta \& Silver, 1998; Silver et al., 1999a, b). In hospitals, silver sulfadiazine is used in burn dressings (George et al., 1997) to prevent nosocomial infections. The most familiar human exposure to silver is with dental amalgams that contain $35 \% \mathrm{Ag}(0)$ and $50 \% \mathrm{Hg}(0)$ 
(a)

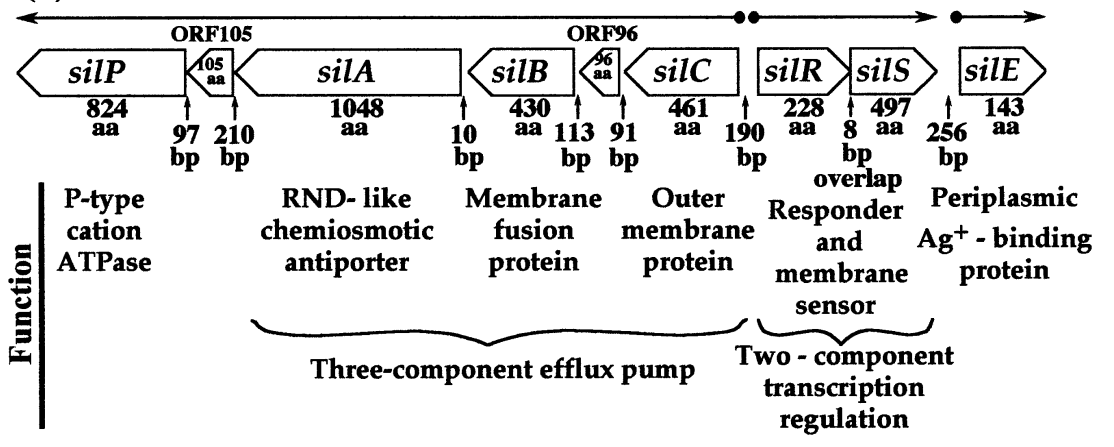

(b)

\section{Comparison of plasmid pMG101 and E.coli strains} K-12 and 0157:H7 chromosomal genes

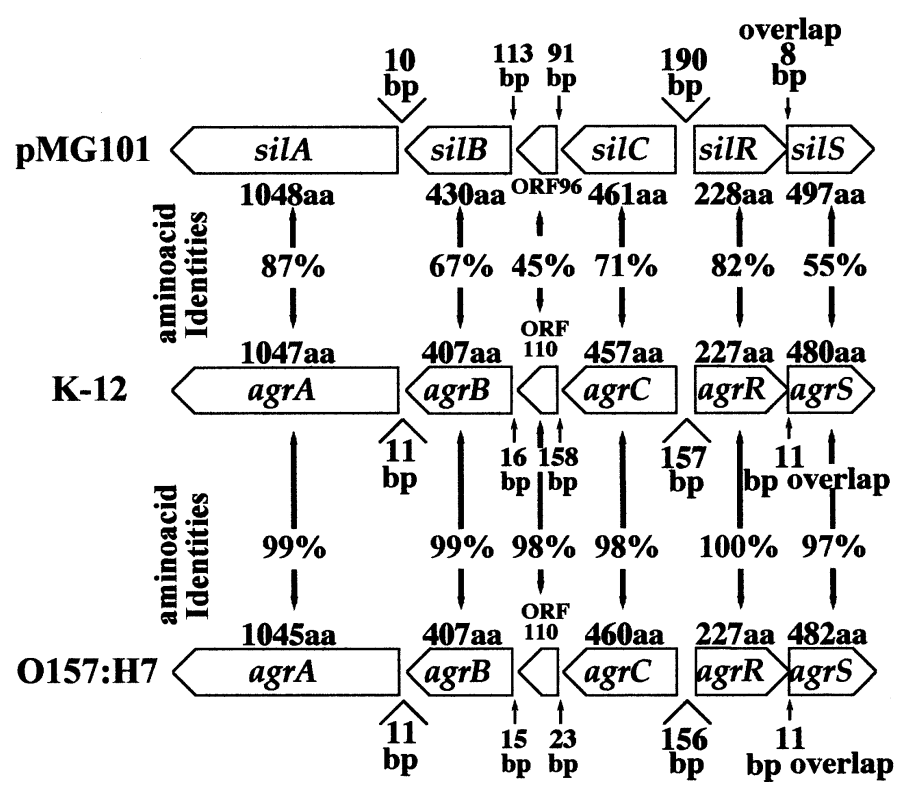

Fig. 1. (a) Genes and protein products of the plasmid sil determinant. Open boxes indicate the nine genes and ORFs. Arrows at the top mark the mRNA transcripts and their orientations. (b) Comparison of the pMG101 sil determinant and the E. coli $\mathrm{K}-12$ and 0157:H7 chromosomal agr homologues. The intergenic gaps are given in bp and the sizes of gene products are given in aa. Amino acid identities (\%) between gene products are shown.
(Dunne et al., 1997). The slow release of $\mathrm{Hg}(0)$ from amalgams is known to select for mercury-resistant bacteria in the gut (Lorscheider et al., 1995). $\operatorname{Ag}(0)$ is also released (Lygre et al., 1999), but whether it has any antimicrobial activity that selects for resistance (perhaps in the mouth) has never been tested.

$\mathrm{Ag}^{+}$ions are highly toxic to all micro-organisms, perhaps due to poisoning of the respiratory electron transport chains and components of DNA replication (Modak \& Fox, 1973; Russell \& Hugo, 1994). Although bacterial $\mathrm{Ag}^{+}$resistance has been periodically reported, the basis was not studied before our recent efforts (Gupta \& Silver, 1998; Gupta et al., 1999; Silver et al., 1999 a b). Human exposure to silver compounds has no serious adverse effect (Russell \& Hugo, 1994). Prolonged silver use occasionally results in 'argyria', a condition with an irreversible grey to blue-black colouring of the skin and mucous membranes due to $\mathrm{Ag}(0)$ or $\mathrm{Ag}_{2} \mathrm{~S}$ deposits. Argyria, however, is mostly of cosmetic concern (Russell \& Hugo, 1994).
Bacterial resistances to different toxic metal ions are encoded by genes located mostly on plasmids, but sometimes on bacterial chromosomes (reviewed by Silver, 1998; Silver \& Phung, 1996; Silver et al., 2000). These resistances are selected frequently when metal salts are used as antiseptics. $\mathrm{Ag}^{+}$-resistant bacteria have been reported periodically from sources such as hospitals and burn wounds where silver toxicity might be expected to select for resistance (Annear et al., 1976; Bridges et al., 1979; Hendry \& Stewart, 1979; McHugh et al., 1975; Pruitt et al., 1998). The physiological, biochemical and molecular basis of bacterial $\mathrm{Ag}^{+}$resistance were not described prior to our studies (Gupta et al., 1999). The first report on the genetic and molecular basis for $\mathrm{Ag}^{+}$resistance concerned a Salmonella typhimurium isolate, from the Massachusetts General Hospital, that killed several patients and required the closing of the burn ward in 1975 (Gupta et al., 1999; McHugh et al., 1975). Plasmid pMG101 from this strain confers resistances to $\mathrm{Ag}^{+}, \mathrm{Hg}^{2+}$ and tellurite, as well as to several antibiotics, for example ampicillin, 
chloramphenicol, tetracycline and streptomycin (Gupta et al., 1999; McHugh et al., 1975).

$\mathrm{The}^{+}{ }^{+}$resistance determinant from pMG101 contains nine ORFs (Fig. 1a) in $12.5 \mathrm{~kb}$ of sequence (GenBank accession no. AF067954; Gupta et al., 1999). The ORFs are arranged in three transcriptional units (Fig. 1a; Gupta et al., 1999). Functions for the seven named genes were assigned on the basis of homologies to known proteins for other metal resistances; the two unnamed ORFs lack such homologues. The first gene identified, silE, encodes a 123 a periplasmic metal-binding protein (Gupta et al., 1999). Upstream from silE and in the same orientation is a presumed two-component gene pair, silRS, encoding a transcriptional regulatory responder protein and a membrane sensor kinase, homologous to other members of the two-component family (Hoch \& Silhavy, 1995).

The remaining six ORFs in the $\mathrm{Ag}^{+}$resistance system are transcribed divergently from silRSE (Fig. 1a; Gupta et al., 1999). The silCBA genes immediately upstream of silRS encode a presumed three-polypeptide chemiosmotic cation/proton antiporter that is a member of the resistance, nodulation and cell division (RND) family of transporters (Saier et al., 1994). This protein complex consists of an inner-membrane proton/cation antiporter (SilA), a membrane fusion protein that spans the inner and outer membranes of Gram-negative bacteria (SilB) and an outer-membrane protein (SilC). Between silC and silB, a 96 codon ORF of unassigned function was identified (Gupta et al., 1999).

The product of the last gene of the $\mathrm{Ag}^{+}$resistance determinant, SilP, is predicted to be a P-type ATPase, a member of the family of heavy-metal resistance ATPases (Rensing et al., 1999; Silver \& Phung, 1996). The $\mathrm{Ag}^{+}$ resistance determinant is unique to date in encoding both a metal-binding protein and two biochemically different efflux mechanisms.

With the characterization of the first $\mathrm{Ag}^{+}$resistance determinant, it is important to understand how widely such systems are to be found in clinical isolates (exposed or not exposed to silver) and in those from silverstressed non-clinical environments. To begin, this study focused on the occurrence of sil genes on different groups of plasmids, rather than on the molecular mechanism of $\mathrm{Ag}^{+}$resistance. Different laboratory stock plasmids of the IncH and IncP incompatibility groups known to carry multiple antibiotic resistance markers were tested for the presence of sil genes. These plasmids were originally isolated from varying geographic locations (see supplementary data at http:// mic.sgmjournals.org or http://www.uic.edu/depts/ $\mathrm{mcmi}$ /individual/gupta/index.htm). The identification and diversity of non-plasmid, chromosomally located sil homologous determinants in genome sequences from different bacteria is also discussed. The data presented are starting points for molecular epidemiological studies with clinical and non-clinical bacterial isolates.

A wide distribution of sil homologous determinants, localized on plasmids or on the bacterial chromosomes might pose a threat toward effective use of silver compounds as antiseptics, analogous to the development of antibiotic-resistant bacteria when antibiotic usage increases (Liu, 1999; Salyers \& Amabile-Cuevas, 1997).

\section{METHODS}

Media, chemicals and culture methods. Luria-Bertani (LB) broth was used (Ausubel et al., 2001). When indicated, the medium was supplemented with ampicillin $\left(100 \mu \mathrm{g} \mathrm{ml}^{-1}\right)$. Recombinant clones were selected on LB agar supplemented with $0 \cdot 15 \mathrm{mM}$ IPTG and $69 \mu \mathrm{M}$ X-Gal. Unless otherwise indicated, all chemicals and reagents were purchased from Difco or Sigma. $\mathrm{Ag}^{+}$resistance of the different E. coli strains was assayed on LB agar plates without added $\mathrm{NaCl}$ (Gupta et al., 1998). Exponential-phase cultures were streaked on plates and incubated at $37^{\circ} \mathrm{C}$ for $16 \mathrm{~h}$ before recording growth.

Bacterial strains. In this study, a series of E. coli strains carrying IncH plasmids from the University of Alberta collection were used (see supplementary data): J53(R476b), J53-2(R826), J53-2(R826-1), J53-2(R828), RG486(MIP233), RG486(pWR23), RG486(MIP235), RG192(TP116), RG1763(R478), RG192(pAS-251-2), RG192(pJT1), J531(R1022), J53(R27); J53-1(pHH1532b-1), JE2571(pHH1457), J62-1(pHH1457-1), J53(MG223), J53(MG224) and J53(MG225). E. coli J53 without a plasmid and J53(pMG101) (Gupta et al., 1999; McHugh et al., 1975) were used as $\mathrm{Ag}^{+}-$ sensitive and -resistant controls, respectively.

\section{Identification and characterization of sil gene homologues}

Dot-blot hybridization. An aliquot $(50 \mu \mathrm{l})$ of each overnight culture was placed on a nylon hybridization membrane using a dot-blot apparatus (Schleicher \& Schuell). The bacterial cells were lysed. The liberated DNA was denatured, neutralized and fixed to the membrane (Ausubel et al. 2001). A ${ }^{32} \mathrm{P}$-labelled silA probe was hybridized to the filterimmobilized DNA. The DNA for the silA probe was generated by PCR amplification using silA gene-specific oligonucleotide primers and radiolabelled with $\left[{ }^{32} \mathrm{P}\right] \mathrm{dCTP}$ by using the MegaPrime DNA labelling kit (Amersham Life Science). Hybridization signals were visualized by exposure to $\mathrm{X}$ OMAT AR film (Eastman Kodak).

PCR. The homologues of pMG101 sil genes were amplified from the boil-lysis supernatants (Ausubel et al., 2001) of overnight culture aliquots, using sil gene-specific primers and PlatiTaq DNA polymerase (Life Technologies). The amplification products were separated on a $0.7 \%$ agarose gel and visualized under UV after staining with ethidium bromide.

Cloning and DNA sequence analysis. PCR products of the sil genes were cloned into the pGEM-Teasy vector (Promega) and transformed into $E$. coli $\mathrm{DH} 5 \alpha$ by electroporation of competent cells (Ausubel et al., 2001; Shigekawa \& Dower, 1988). Plasmid DNA was isolated (Ausubel et al., 2001) and cloned DNA was sequenced by using M13 universal forward and reverse sequencing primers by the dideoxy chain termination method using an $\mathrm{ABI}$ automated sequencer at the University of Illinois Sequencing Facility. DNA sequences were compared and analysed using CLUSTAL $\mathrm{X}$ version $1.64 \mathrm{~b}$ and DNA Sequencher version 3.1.1 software.

Transcript analysis. Total RNA was isolated from E. coli strain J53(R476b) and J53(pMG101) cells exposed to 0 or $25 \mu \mathrm{M} \mathrm{Ag}^{+}$for $2 \mathrm{~h}$ at $37^{\circ} \mathrm{C}$ during growth in LB broth. RNA was isolated using the RNeasy total RNA preparation kit (Qiagen) and treated with RNase-free DNase (Life Technologies). For reverse transcriptase (RT)-PCR, $1 \mu \mathrm{g}$ RNA was 
used for cDNA synthesis at $42{ }^{\circ} \mathrm{C}$ using Superscript II RT according to the manufacturer's protocol (Life Technologies). Subsequent PCR was performed using PlatiTaq DNA polymerase (Life Technologies). For quantitation of fluorescence intensities of the RT-PCR products, the ethidium-bromidestained agarose gel was recorded using a Sony CCD (chargecoupled device) camera attached to the Nucleotech gel documentation system. The fluorescence intensities were measured using GelExpert 97 version 2.0 software.

Construction of agrA deletion mutant and growth measurements. Chromosomal agrA was deleted by insertion of an antibiotic (kanamycin) resistance marker. The kanamycin cassette DNA contained flanking sequences homologous to $\operatorname{agr} A$ and was incorporated into the chromosome using homologous recombination as described by Datsenko \& Wanner (2000). DH5 $\alpha \Delta a g r A$ (pAG59) carries a pUC57T (MBI Fermentas) derivative containing a PCR DNA fragment for the agr $A B C$ genes. Growth was measured for E. coli strains K-12 DH5 $\alpha$, DH5 $\alpha \Delta a g r A$ and DH5 $\alpha \Delta a g r A$ (pAG59) by inoculation of $\mathrm{LB}$ broth $(-\mathrm{NaCl})$ containing different concentrations of $\mathrm{AgNO}_{3}$ with an exponential-phase culture at $0 \cdot 2$ Klett turbidity units. The cultures were incubated with shaking for $16 \mathrm{~h}$ at $37^{\circ} \mathrm{C}$ prior to measurements with a Klett turbidity meter.

\section{RESULTS}

\section{Plasmid sil determinants}

Plasmid pMG101 (harbouring the sil system) has now been assigned to the IncHI2 incompatibility group (data not shown; incompatibility and surface exclusion

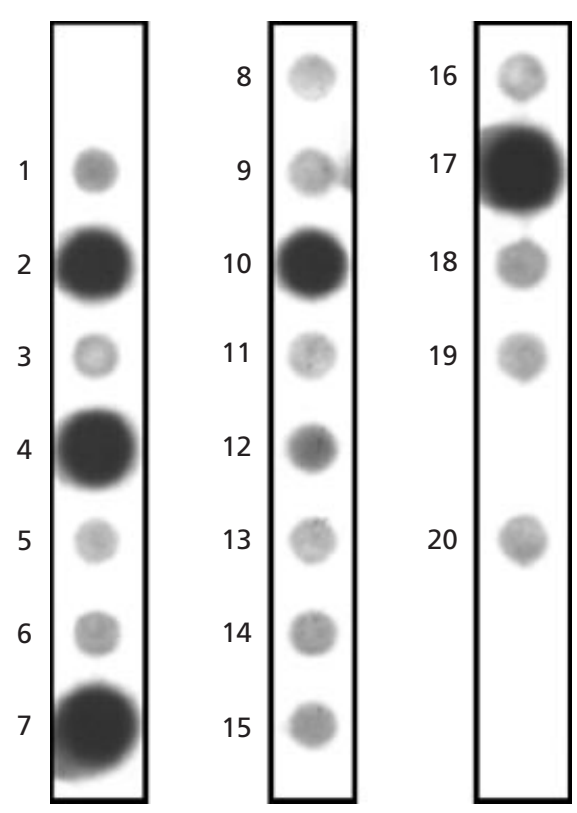

Fig. 2. Dot blot DNA-DNA hybridization with the silA probe of DNA released from cultures of $E$. coli strains. Spots: 1, J532(R828); 2, J53(R476b); 3, RG192(TP116); 4, RG486(MIP235); 5, J53-1(R1022); 6, J53-2(R826); 7, RG486(pWR23); 8, RG192(pJT1); 9, J53(MG225)； 10，RG1763(R478); 11，J53(MG224); 12, RG192(pAS-251-2)；13，J53(R27)； 14，J53-1(pHH1532b-1)；15， J53-2(R826-1)；16，J53(MG223)；17，RG486(MIP233)；18，J621 (pHH1457-1); 19, JE2571(pHH1457); 20, negative control strain J53. measurements). The IncH incompatibility group of plasmids consists of two compatible groups, IncHI and IncHII. The IncHI group contains three self-incompatible subgroups, IncHI1, IncHI2 and IncHI3. Nineteen plasmids belonging to different IncH incompatibility divisions were analysed by dot blot DNA-DNA hybridization and homologues for the pMG101 silA gene were identified in five IncHI (three IncHI2 and two IncHI3) plasmid-carrying strains (Fig. 2). Neither of the two IncHII plasmids tested showed positive hybridization (Fig. 2, spots 18 and 19). In addition, six IncP group plasmids were tested and did not hybridize (data not shown). The positively hybridizing strains were E. coli strains J53(R476b), RG486(MIP233), RG486(pWR23), RG486(MIP235) and RG1763(R478). The probe hybridization was at $65^{\circ} \mathrm{C}$. To pick up all cross-hybridization, low-stringency wash conditions at $25^{\circ} \mathrm{C}$ were used. These conditions gave low-level hybridization to DNA from other E. coli strains on the filter (including the plasmidless control strain E. coli J53; Fig. 2, spot 20), which probably reflects the homology between the plasmid silA gene and the homologous E. coli K-12 chromosomal agrA gene (see below).

Next, homologues for three additional sil genes, silP, silS and silE (each representing a separate transcript for the pMG101 system; Gupta et al., 1999), were identified by PCR (data not shown) in the strains that hybridized positively to ${ }^{32} \mathrm{P}$-labelled silA DNA probe (Fig. 2). All the PCR primers were identical to the DNA sequence for the corresponding sil genes of pMG101. PCR amplification products of the predicted sizes, 2659, 1549 and $469 \mathrm{bp}$, were obtained for the IncHI silP, silS and silE genes, respectively (data not shown).

\section{Sequences of plasmid-located sil genes}

The silP, sils and silE genes amplified by PCR from E. coli strains J53(R476b), RG486(MIP233), RG486(pWR23), RG486(MIP235) and RG1763(R478) were cloned and the DNA for each new sil gene was sequenced. The sequences were compared with pMG101 sequences (Table 1). The DNA and protein alignments from which the detailed data in Table 1 were calculated are given in supplementary data. The silE genes from plasmids in strains J53(R476b), RG486(MIP233) and RG486(MIP235) were identical in DNA sequence (Table 1) to pMG101 silE; silE from strains RG1763(R478) and RG486(pWR23) differed from silE of pMG101 at 19 or 1 positions, respectively (Table 1 ). The 10 predicted histidine residues of SilE that are involved in $\mathrm{Ag}^{+}-$ protein binding (Gupta et al., 1999; Silver et al., 1999a) are conserved in the SilE products from the additional IncHI plasmids (see supplementary data).

None of the new silP and sils genes were identical to those of pMG101. Four of the five new plasmid silP genes were more similar in sequence to silP of pMG101 than was silP of R476b (Table 1). The silS variants each differed from one another in similar numbers of positions (Table 1; see supplementary data). The 
Silver resistance genes in $\mathrm{IncH}$ plasmids

Table 1. DNA and amino acid comparison of three sil gene homologues from IncHI plasmids

\begin{tabular}{|c|c|c|c|c|c|c|c|c|c|c|c|c|c|c|}
\hline \multirow{3}{*}{$\begin{array}{l}\text { Gene and } \\
\text { plasmid }\end{array}$} & \multicolumn{6}{|c|}{ Nucleotide differences } & \multicolumn{6}{|c|}{ Coding differences } & \multirow{2}{*}{\multicolumn{2}{|c|}{$\begin{array}{c}\text { Identity to } \\
\text { pMG101 (\%) }\end{array}$}} \\
\hline & \multirow{2}{*}{ pMG101 } & \multirow{2}{*}{$\mathrm{R} 476 \mathrm{~b}$} & \multirow{2}{*}{ MIP233 } & \multirow{2}{*}{ pWR23 } & \multirow{2}{*}{ MIP235 } & \multirow{2}{*}{$\mathrm{R} 478$} & \multirow{2}{*}{ pMG101 } & \multirow{2}{*}{$\mathrm{R} 476 \mathrm{~b}$} & \multirow{2}{*}{ MIP233 } & \multirow{2}{*}{ pWR23 } & \multirow{2}{*}{ MIP235 } & \multirow{2}{*}{$\mathrm{R} 478$} & & \\
\hline & & & & & & & & & & & & & DNA & Protein \\
\hline \multicolumn{15}{|c|}{ silE ( $424 \mathrm{bp}$ sequenced out of $429 \mathrm{bp}$ ) } \\
\hline pMG101 & - & 0 & 0 & 19 & 0 & 1 & - & 0 & 0 & 9 & 0 & 1 & - & - \\
\hline $\mathrm{R} 476 \mathrm{~b}$ & 0 & - & 0 & 19 & 0 & 1 & 0 & - & 0 & 9 & 0 & 1 & 100 & 100 \\
\hline MIP233 & 0 & 0 & - & 19 & 0 & 1 & 0 & 0 & - & 9 & 0 & 1 & 100 & 100 \\
\hline pWR23 & 19 & 19 & 19 & - & 19 & 20 & 9 & 9 & 9 & - & 9 & 10 & $95 \cdot 5$ & $92 \cdot 9$ \\
\hline MIP235 & 0 & 0 & 0 & 19 & - & 1 & 0 & 0 & 0 & 9 & - & 1 & 100 & 100 \\
\hline R478 & 1 & 1 & 1 & 20 & 1 & - & 1 & 1 & 1 & 10 & 1 & - & $99 \cdot 7$ & $99 \cdot 3$ \\
\hline \multicolumn{15}{|c|}{ silP (1256 bp sequenced out of $2475 \mathrm{bp}$ ) } \\
\hline pMG101 & - & 53 & 8 & 7 & 8 & 6 & - & 29 & 6 & 5 & 6 & 6 & - & - \\
\hline $\mathrm{R} 476 \mathrm{~b}$ & 53 & - & 47 & 48 & 48 & 49 & 29 & - & 23 & 24 & 25 & 25 & $95 \cdot 8$ & $91 \cdot 9$ \\
\hline MIP233 & 8 & 47 & - & 3 & 4 & 4 & 6 & 23 & - & 1 & 2 & 2 & $99 \cdot 4$ & $98 \cdot 3$ \\
\hline pWR23 & 7 & 48 & 3 & - & 1 & 1 & 5 & 24 & 1 & - & 1 & 1 & $99 \cdot 4$ & $98 \cdot 6$ \\
\hline MIP235 & 8 & 48 & 4 & 1 & - & 2 & 6 & 25 & 2 & 1 & - & 2 & $99 \cdot 4$ & $98 \cdot 3$ \\
\hline R478 & 6 & 49 & 4 & 1 & 2 & - & 6 & 25 & 2 & 1 & 2 & - & $99 \cdot 5$ & $98 \cdot 3$ \\
\hline \multicolumn{15}{|c|}{ sils (1064 bp sequenced out of 1494 bp) } \\
\hline pMG101 & - & 46 & 39 & 48 & 34 & 34 & - & 13 & 13 & 18 & 12 & 12 & - & - \\
\hline R476b & 46 & - & 15 & 22 & 14 & 14 & 13 & - & 2 & 7 & 3 & 3 & $95 \cdot 7$ & $96 \cdot 1$ \\
\hline MIP233 & 39 & 15 & - & 25 & 9 & 9 & 13 & 2 & - & 7 & 1 & 1 & $96 \cdot 3$ & $96 \cdot 1$ \\
\hline pWR23 & 48 & 22 & 25 & - & 18 & 18 & 18 & 7 & 7 & - & 8 & 8 & $95 \cdot 5$ & $94 \cdot 7$ \\
\hline MIP235 & 34 & 14 & 9 & 18 & - & 0 & 12 & 3 & 1 & 8 & - & 0 & $96 \cdot 8$ & $96 \cdot 4$ \\
\hline R478 & 34 & 14 & 9 & 18 & 0 & - & 12 & 3 & 1 & 8 & 0 & - & $96 \cdot 8$ & $96 \cdot 4$ \\
\hline
\end{tabular}

sequences from all six sil-positive IncHI plasmids (including pMG101) were $0,0.3$ or $4 \%$ different at the nucleotide level for silE, $0 \cdot 5-4 \%$ for silP and 3-4\% for sils (Table 1; see supplementary data). The corresponding protein products differed in slightly higher percentages of positions (Table 1), since many of the nucleotide changes resulted in coding changes (see supplementary data). In the silP gene products, the novel SilP N-terminal sequence, $\mathrm{His}_{5} \mathrm{AspHis}_{2}$, implicated as a determinant of cation specificity or for modulation of transport, was conserved. The high level of sequence identity between sil gene PCR products shows that the amplified products correspond to plasmid-encoded sequences and are not from the E. coli K-12 chromosome (see below).

\section{The order of sil genes is the same on different plasmids}

In pMG101, the genes $\operatorname{silP}(\mathrm{ORF105)} A B(\mathrm{ORF96)} C$ are oriented divergently from silRSE. The sil gene order and orientation on the five new IncHI plasmids were determined by PCR amplification using one primer located in the $5^{\prime}$ region of one gene and a second primer located toward the $3^{\prime}$ end of a downstream gene. With primers in the $5^{\prime}$ region of silR and the $3^{\prime}$ end of sils, a PCR product of approximately $2184 \mathrm{bp}$ was obtained from the six sil-positive plasmids (Fig. 3a), showing that silR and sils are contiguous and similarly oriented. With primers in the $5^{\prime}$ region of silR and the $3^{\prime}$ end of silE (see
Fig. 1a), a PCR product of approximately 2812 bp was obtained from all six plasmids (Fig. 3b), indicating that silRS was contiguous with and in the same orientation as silE. PCR products of the expected size (6424 bp) were obtained with primers in the $5^{\prime}$ region of silA and the $3^{\prime}$ end of silP (Fig. 3c). These results show that silA and silP are contiguous and similarly oriented in all six plasmids. The organization of the sil genes on the IncHI plasmids from E. coli strains J53(R476b), RG486(MIP233), RG486(pWR23), RG486(MIP235) and RG1763(R478) is therefore considered to be the same as the sil genes on pMG101.

\section{Silver resistance and transcription from the sil genes}

Growth. Silver resistance levels of E. coli strains J53(R476b) (Fig. 4), RG486(MIP233), RG486(pWR23), RG486(MIP235) and RG1763(R478) (additional data not shown) were measured. E. coli strains J53 and J53(R476b) grew on plates supplemented with up to $100 \mu \mathrm{M} \mathrm{Ag}^{+}$(Fig. 4a, lanes 1 and 2), whereas strain J53(pMG101) grew above $600 \mu \mathrm{M} \mathrm{Ag}^{+}$(Fig. 4a, lane 3;

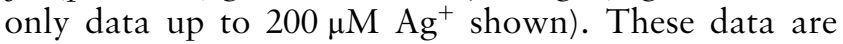
representative of three independent experimental results. The growth of E. coli strains RG486(MIP233), RG486(pWR23), RG486(MIP235) and RG1763(R478) was similar to that for J53(R476b) (data not shown). The absence of a high pMG101-like level of $\mathrm{Ag}^{+}$ resistance with $E$. coli strains carrying the five new IncHI plasmids, although all of the sil genes are present, might 


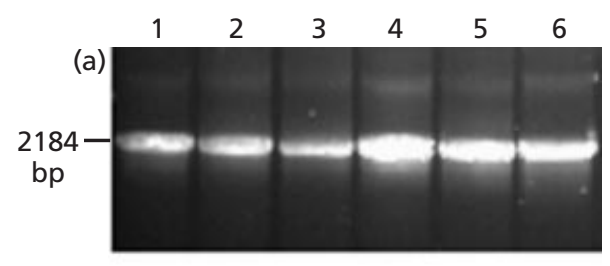

$\operatorname{sil} 5^{\prime}-\operatorname{sils} 3$
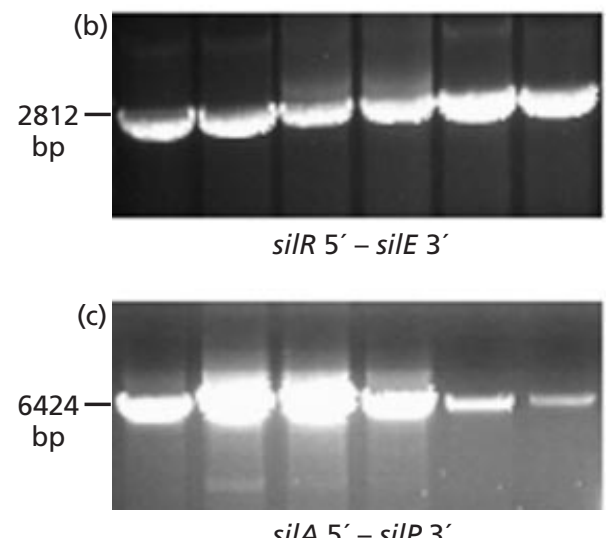

$\operatorname{silA} 5^{\prime}-\operatorname{sil} 3^{\prime}$

Fig. 3. $P C R$ products spanning different genes were obtained for (a) silR sils, (b) silR silS sile and (c) silA silP from different IncHI plasmids and visualized on ethidium bromide-stained agarose gels. The PCR products were from E. coli strains. J53(pMG 101) (lane 1), J53(R476b) (2), RG486(MIP233) (3), RG486(pWR23) (4), RG486(MIP235) (5) and RG1763(R478) (6). The sizes of pMG101 products are indicated and the primers used for PCR are given below each panel.

result from low-level gene expression and a history of not having been selected for $\mathrm{Ag}^{+}$resistance in laboratory passage. To test if a higher level of $\mathrm{Ag}^{+}$resistance is obtained after induction by $\mathrm{Ag}^{+}$, exponential-phase cultures of E. coli strains J53, J53(pMG101) and $\mathrm{J} 53(\mathrm{R} 476 \mathrm{~b})$ were grown with $25 \mu \mathrm{M} \mathrm{Ag}{ }^{+}$for $2 \mathrm{~h}$ and then streaked on LB agar plates containing higher concentrations of $\mathrm{Ag}^{+}$(Fig. 4b). Growth of E. coli J53 occurred only up to $100 \mu \mathrm{M} \mathrm{Ag}^{+}$(Fig. 4b, lane 1), similar to results with uninduced cells (Fig. 4a, lane 1). However, growth of strain J53(R476b) occurred up to $400 \mu \mathrm{M} \mathrm{Ag}^{+}$(Fig. 4b, lane 2), but not at $600 \mu \mathrm{M} \mathrm{Ag}^{+}$ (data not shown). E. coli J53(pMG101) grew at $400 \mu \mathrm{M}$ $\mathrm{Ag}^{+}$(Fig. 4b, lane 3) and above (data not shown). These data show that induction with $\mathrm{Ag}^{+}$increased the $\mathrm{Ag}^{+}$ resistance of E. coli strain J53(R476b), suggesting that gene expression increased.

Transcript analysis. To test sil gene expression at the transcriptional level, total RNA was isolated from cultures of E. coli J53(R476b) and J53(pMG101), grown with and without $25 \mu \mathrm{M} \mathrm{Ag}{ }^{+}$for $2 \mathrm{~h}$ and the RNA analysed by RT-PCR (Gupta, 1999; Gupta et al., 1999). For each RT reaction, equivalent amounts of RNA extracted from cultures grown in the presence and in the absence of $\mathrm{Ag}^{+}$were used. As an internal RNA control, a primer for the $3^{\prime}$ region of the E. coli $16 \mathrm{~S}$ rRNA gene was included in each $\mathrm{RT}$ reaction, which also included primers corresponding to the $3^{\prime}$ regions of silC, silS or silE, respectively. Thus each RT reaction included its own internal control (shown in Fig. 5d). Next, a pair of PCR primers, corresponding to the $5^{\prime}$ and $3^{\prime}$ regions of silC, silR, silE or control E. coli $16 \mathrm{~S}$ rRNA genes, were used for amplification of single gene products from the cDNA (Fig. 5). The E. coli $16 \mathrm{~S}$ rRNA gene control (Fig. $5 \mathrm{~d}$ ) demonstrated that equivalent amounts of RNA were taken for the RT reactions and therefore any differences in intensities of the PCR products with sil genes represent changes in transcript abundance.

The PCR products for the silR genes (Fig. 5a) were obtained from the RT product for which the primer for the $3^{\prime}$ region of sils was used. This result confirms the contiguity of silS and silR (Fig. 1; Gupta, 1999; Gupta et al., 1999) for plasmid R476b. The silR PCR products generated for the two plasmids and from induced and uninduced cultures were all approximately equal in amount (Fig. 5a). A comparison of the fluorescence intensities of the PCR products showed that the differences (a range of $15 \%$ ) were within experimental error (analysis not shown). It appears that that there was no induction of transcription for silRS with both plasmids after exposure to $\mathrm{Ag}^{+}$.

Quantitation of the PCR products for silC indicated 1.8times more silC transcript with RNA from induced strain J53(R476b) cells than from uninduced cells (Fig. 5 b, lanes 3 and 4 ; analysis not shown) and equivalent amounts of silC RNA with uninduced and $\mathrm{Ag}^{+}$-induced cultures of J53(pMG101) (Fig. 5b, lanes 1 and 2). The diffusion of the band in Fig. 5(b) lane 1 is thought to be an artifact of the gel and equivalent total fluorescence was obtained for lanes 1 and 2. Furthermore, the amount of silC PCR product from induced strain J53(R476b) cells was similar to that from pMG101. This indicates that silC transcription from strain J53(R476b) is low, but can be induced, while in J53(pMG101) silC transcription is constitutive and high. These data represent a first step toward explaining the differences in $\mathrm{Ag}^{+}$ resistance levels between the two strains.

The PCR products for silE show a lower but 1.32-fold inducible level of transcription with strain J53(R476b) (Fig. 5c, lanes 3 and 4; analysis not shown) compared with a higher and constitutive level of transcription with strain J53(pMG101) (Fig. 5c, lanes 1 and 2). The transcript level from induced cells of strain J53(R476b) (Fig. 5c, lane 4) was $73 \%$ of that from J53(pMG101) cells, perhaps consistent with the lower resistance level of J53(R476b) (Fig. 4b).

\section{Chromosomal homologues of the sil determinant}

The sil determinant from pMG101 contains seven named genes (and two ORFs of unassigned function) (Fig. 1a; Gupta et al., 1999). The closest homologues for silAB(ORF96)CRS in the GenBank database are from the published E. coli $\mathrm{K}-12$ and $\mathrm{O} 157: \mathrm{H} 7$ chromosomes (Blattner et al., 1997; Perna et al., 2001). These ORFs are listed in GenBank as hypothetical genes and are desig- 
(a)
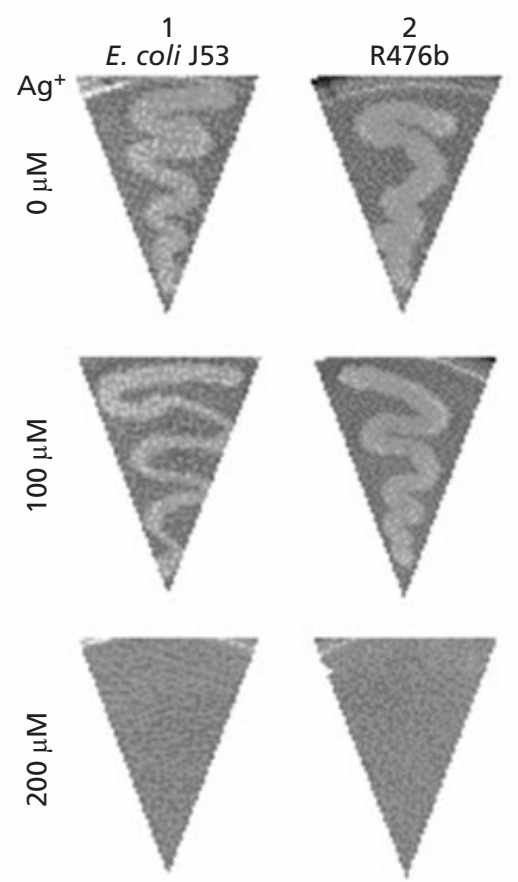

(b)
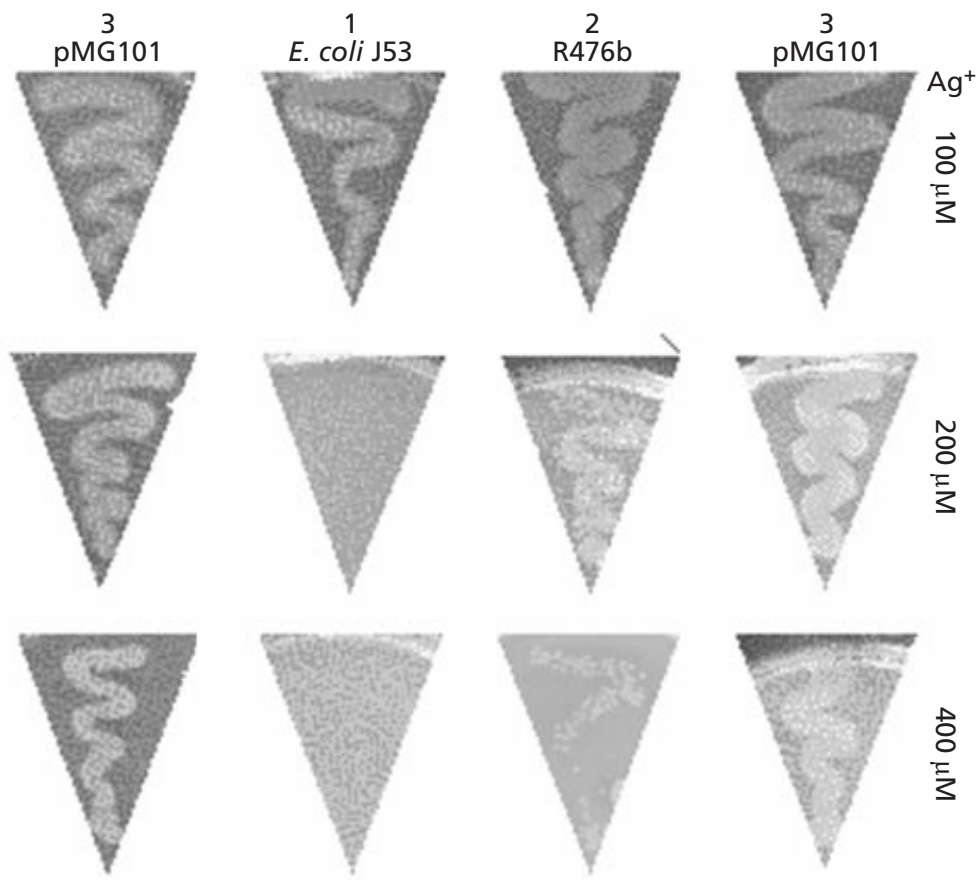

Fig. 4. $\mathrm{Ag}^{+}$resistance. Exponential-phase cultures, grown (a) in the absence of $\mathrm{Ag}^{+}$or (b) for $2 \mathrm{~h}$ with $25 \mu \mathrm{M} \mathrm{Ag}^{+}$, were streaked on LB agar supplemented with $\mathrm{Ag}^{+}$. Growth was measured with E. coli strains J53 (column 1), J53(R476b) (2) and J53(pMG101) (3). Triangular 'slices' of the agar plates with or without bacterial growth and the concentration of $\mathrm{Ag}^{+}$ added to each plate are shown.
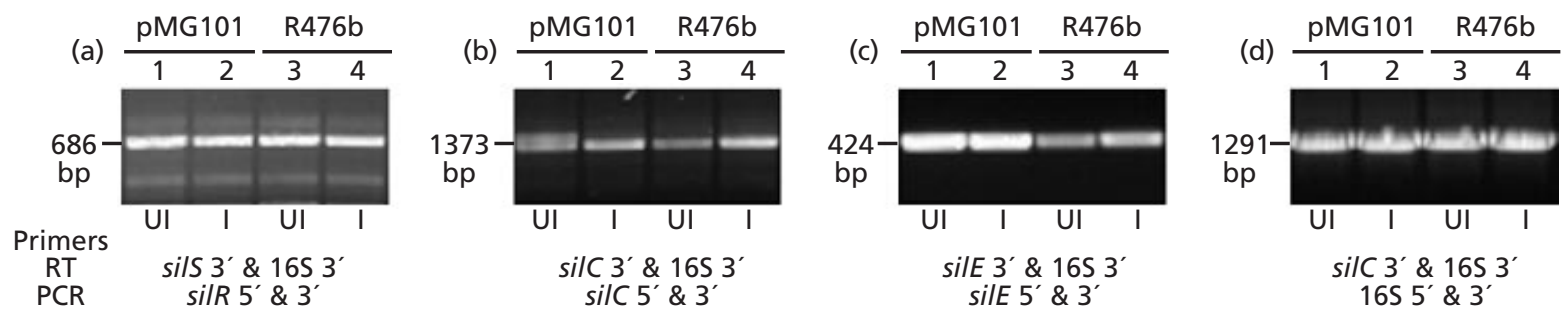

Fig. 5. RT-PCR analysis of transcripts. The transcripts for (a) silR, (b) silC, (c) silE and (d) E. coli 16S rRNA genes were analysed in total RNA isolated from E. coli strains J53(pMG101) (lanes 1 and 2) and J53(R476b) (3 and 4). RNA was isolated from cultures uninduced (UI) or induced (I) with $25 \mu \mathrm{M} \mathrm{Ag}^{+}$for $2 \mathrm{~h}$ during growth. The primers used for the RT reaction and for subsequent PCR amplifications are given.

nated $y b d E, y l c D, y l c C, y l c B, y l c A$ and $y b c Z$, respectively (for E. coli K-12, GenBank accession no. AE000162, amino acid accession nos 1786788-1786783; for E. coli O157:H7: GenBank accession nos AE005236 and AE005237, amino acid accession nos AAG54903.1AAG54908.1; respectively) (Blattner et al., 1997; Perna et al., 2001). Based on the data presented in this paper, we propose to name these genes agrA ( $y b d E)$, agrB $\left(y l_{c} D\right)$, ORF110 $\left(y l_{c} C\right), \operatorname{agr} C(y l c B), \operatorname{agrR}(y l c A)$ and agr $S$ (ybcZ) (agr for $\mathrm{Ag}^{+}$resistance; Fig. 1b). The mnemonic agr is introduced rather than calling the chromosomal genes sil, as it has not yet been demon- strated whether they are paralogous or only orthologous in function. The E. coli chromosomal sil gene homologues are present on what is being called the 'common E. coli backbone' of $2.6 \mathrm{Mb}$ shared between the two strains (Perna et al., 2001). Between the two chromosomal sets, only the SilR homologues (AgrR) are 100\% identical while the other homologue pairs vary between 0.74 and $2.3 \%$ at the amino acid level and to similar degrees at the nucleotide level. The chromosomal genes are oriented in the same direction as the plasmid sil genes and the spacing between genes in most cases is rather similar (Fig. 1b). The amino acid identities 


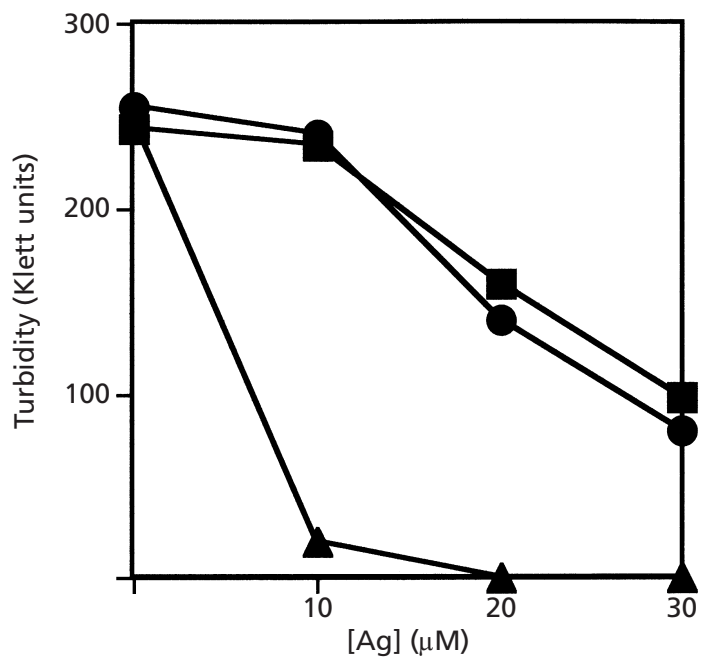

Fig. 6. Growth of $E$. coli strains $\mathrm{DH} 5 \alpha(\boldsymbol{\square}), \mathrm{DH} 5 \alpha \Delta \operatorname{\Delta ag} A(\boldsymbol{\Delta})$ and DH5 $\alpha \Delta$ agrA(pAG59) (O) in LB broth $(-\mathrm{NaCl})$ containing different concentrations of $\mathrm{AgNO}_{3}$. The cultures were incubated for $16 \mathrm{~h}$ at $37^{\circ} \mathrm{C}$ prior to measurements with a Klett turbidity meter.

between translation products of the plasmid sil determinants and the putative paralogous E. coli chromosomal products are shown in Fig. 1(b) and detailed alignments between the sil and the chromosomally encoded products are available in the supplementary data.

The E. coli chromosomal genes are proposed to encode a three-polypeptide cation efflux transporter (AgrABC, equivalent to SilABC), plus a two-component kinase/ responder transcriptional regulatory pair (AgrRS, equivalent to SilRS). These five genes and their products are related to those of the $c z c A B C R S$ (for $\mathrm{Cd}^{2+}, \mathrm{Zn}^{2+}$ and $\mathrm{Co}^{2+}$ resistances) plasmid system of Ralstonia (Nies, 1995). Between ORFs $\operatorname{agr} C$ and $\operatorname{agr} B$ is ORF110, which is homologous to ORF96 in the sil determinant (Fig. 1a and $b$ ). An equivalent ORF is not present in the homologous CzcABCRS system. A deletion in $\operatorname{agr} A$ (homologous to silA) on the E. coli chromosome resulted in $\mathrm{Ag}^{+}$hypersensitivity (Fig. 6), but did not change the sensitivity level to high $\mathrm{Cd}^{2+}$ and $\mathrm{Cu}^{2+}$. Similar observations have also been made by Franke et al. (2001). The introduction of an intact agrA gene on a plasmid restored resistance to silver (Fig. 6). These results suggest that the chromosomal genes also function for $\mathrm{Ag}^{+}$ resistance.

In addition to the E. coli $\mathrm{K}-12$ and $\mathrm{O} 157: \mathrm{H} 7$ chromosomal agr genes, sil gene homologues are found in the partial genomes of Salmonella paratyphi, S. typhimurium and Klebsiella pneumoniae. The genome sequences are available from the Washington University Genome Sequencing Center (http:// genome.wustl.edu/gsc). In $K$. pneumoniae, there are homologues for all seven sil genes (predicted products with over $90 \%$ amino acid identity) and the novel features of specific Sil proteins are conserved, for example the $\mathrm{His}_{5} \mathrm{AspHis}_{2} \mathrm{~N}$-terminal motif of SilP and the 10 specifically placed histidine residues of SilE. In contrast, the homologues from Salmonella are less similar to those of pMG101 (predicted products only $30-40 \%$ identical at the amino acid level) and the Salmonella P-type ATPase homologue lacks the $\mathrm{His}_{5}$ AspHis $_{2}$ motif.

\section{DISCUSSION}

pMG101 belongs to the IncHI2 incompatibility group of plasmids (D. E. Taylor, unpublished data), which are large multi-antibiotic resistance plasmids found widely in the Enterobacteriaceae and that are transferred by conjugation only at lower temperatures (see references at http://www.uic.edu/depts/mcmi/individual/ gupta/index.htm). The identification of new sil genes on five additional plasmids, all of which are IncHI2 or IncHI3, and homologous genes on the chromosomes of E. coli K-12 and O157:H7 and other bacteria raises important concerns about the development of $\mathrm{Ag}^{+}-$ resistant bacteria. Strains carrying the five IncHI plasmids showed moderate $\mathrm{Ag}^{+}$resistance (Fig. 4 and data not shown). $\mathrm{Ag}^{+}$resistance of representative strain $\mathrm{J} 53(\mathrm{R} 476 \mathrm{~b})$ increased upon induction with $\mathrm{Ag}^{+}$. This induction coincided with a measured increase in transcription of sil genes and, hence, likely an increase in the cellular proteins (one for $\mathrm{Ag}^{+}$binding and the other for $\mathrm{Ag}^{+}$efflux).

pMG101 conferred strong $\mathrm{Ag}^{+}$resistance and a higher constitutive level of transcription, compared to plasmid R476b. It is unclear and remains to be tested why plasmid R476b shows lesser resistance to $\mathrm{Ag}^{+}$and a lower level of constitutive, but inducible expression. The newly identified sil genes may not provide a high level of $\mathrm{Ag}^{+}$resistance in the strains as isolated, but may provide a selective advantage to the bacteria that possess these genes on exposure to $\mathrm{Ag}^{+}$. Mutations that allow higher expression from these genes and increased resistance would be selected. $\mathrm{Ag}^{+}$-resistant clinical E. coli isolates selected by step-wise exposure to higher concentrations of $\mathrm{Ag}^{+}$showed active efflux of $\mathrm{Ag}^{+}$( $\mathrm{Li}$ et al., 1997). It is possible that the pMG101 sil system has been already selected in this regard by repeated growth on high concentrations of $\mathrm{Ag}^{+}$during the more than 25 years of laboratory culturing since it was isolated. It is also notable that pMG101 was found in a Salmonella isolate from a burn ward where silver sulfadiazine was used to prevent nosocomial infections (McHugh et al., 1975).

Contiguous homologues for five of the seven sil genes were identified on the E. coli $\mathrm{K}-12$ and O157:H7 chromosomes. There are no ORFs on the E. coli K-12 or O157: H7 chromosomes homologous to silE, suggesting that this gene was added late to the plasmid system. $E$. coli $\mathrm{K}-12$ has six genes for P-type ATPases, and the closest with regard to amino acid product sequence on both the K-12 and O157:H7 chromosomes to that of pMG101 SilP is ybaR (GenBank accession U58330; 
renamed copA; Rensing et al., 2000), which is involved in $\mathrm{Cu}^{+}$efflux. copA is located approximately $60 \mathrm{~kb}$ away from the agrABORF110CRS system. copA may also mediate efflux of $\mathrm{Ag}^{+}$since a deletion in $\operatorname{cop} A$ resulted in hypersensitivity to $\mathrm{Ag}^{+}$(A. Gupta, data not shown) as well as to $\mathrm{Cu}^{+}$(Rensing et al., 2000). The $\mathrm{Ag}^{+}$efflux reported in clinical E. coli isolates (Li et al., 1997) may involve the homologous agrAB(ORF110)CRS chromosomal regions (Fig. 1b). The likely cation substrates for efflux by the chromosomal agr system are $\mathrm{Ag}^{+}$ and $\mathrm{Cu}^{+}$, since a shared $\mathrm{Ag}^{+} / \mathrm{Cu}^{+}$efflux transporter has been identified in Enterococcus (Solioz \& Odermatt, 1995) and a deletion in $\operatorname{agr} A$ renders the cell hypersensitive to $\mathrm{Ag}^{+}$(Fig. 6). The differences between the two E. coli K-12 and O157:H7 chromosomal agr gene systems, although small (Fig. 1b), are sufficient to suggest that a common ancestor of both strains, that are predicted to have diverged about 4.5 million years ago (Perna et al., 2001), already contained the $a g r$ gene system. The differences between the two E. coli chromosomal systems are similar in percentage to those seen between the sil systems from different plasmids of the IncHI group, as reported in this study (Table 1). This suggests that the plasmid sil gene determinants have also been present for a sufficiently long time to establish heterogeneity in DNA and protein sequences. With increasing numbers of bacterial genomes being sequenced and homologues of the sil system being found in increasing numbers, it is reasonable to designate the chromosomal genes as $a g r$ to allow more accurate subsequent annotation of new DNA sequences.

The availability of DNA sequences for sil genes on six IncHI plasmids and identification of close homologues on bacterial chromosomes are starting points for molecular epidemiological studies of sil genes in clinical and environmental isolates of concern that may or may not have been exposed to silver. Such molecular diversity studies of the sil genes will be helpful in addressing questions regarding nosocomial infections, toxic metal bioremediation and the effective use of $\mathrm{Ag}^{+}$as a biocide.

\section{ACKNOWLEDGEMENTS}

We thank William Hendrickson, Tapan K. Misra, Dietrich H. Nies, Christopher Rensing and William Walden for helpful discussions. This work was supported by grants from the US Department of Energy and the Canadian Institutes of Health Research (MT6200). D.E.T. acknowledges support as a Scientist with the Alberta Heritage Foundation for Medical Research.

\section{REFERENCES}

Annear, D. I., Mee, B. J. \& Bailey, M. (1976). Instability and linkage of silver resistance, lactose fermentation and colony structure in Enterobacter cloacae. J Clin Pathol 29, 441-443.

Ausubel, F. M., Brent, R., Kingston, R. E., Moore, D. D., Seidman, J. G., Smith, J. A. \& Struhl, K. (editors) (2001). Current Protocols in Molecular Biology. New York: Wiley.
Blattner, F. R., Plunkett, G. I., Bloch, C. A. \& 14 other authors (1997). The complete genome sequence of Escherichia coli K12. Science 277, 1453-1474.

Bridges, K., Kidson, A., Lowbury, E. J. L. \& Wilkins, M. D. (1979). Gentamicin- and silver-resistant Pseudomonas. Brit Med J 1, 446-449.

Datsenko, K. A. \& Wanner, B. L. (2000). One-step inactivation of chromosomal genes in Escherichia coli K-12 using polymerase chain reaction products. Proc Natl Acad Sci U S A 97, 6640-6645.

Dunne, S. M., Gainsford, I. D. \& Wilson, N. H. (1997). Current materials and techniques for direct restorations in posterior teeth. Part 1: Silver amalgam. Int Dent J 47, 123-136.

Franke, S., Grass, G. \& Nies, D. H. (2001). The product of the $y b d E$ gene of the Escherichia coli chromosome is involved in detoxification of silver ions. Microbiology 147, 965-972.

George, N., Faoagali, J. \& Muller, M. (1997). Silvazine (silver sulfadiazine and chlorhexidine) activity against 200 clinical isolates. Burns 23, 493-495.

Gupta, A. (1999). RT-PCR: characterization of long multi-gene operons and multiple transcript gene clusters in bacteria. BioTechniques 27, 966-972.

Gupta, A. \& Silver, S. (1998). Silver as a biocide: will resistance become a problem? Nat Biotechnol 16, 888 .

Gupta, A., Maynes, M. \& Silver, S. (1998). The effects of halides on plasmid silver resistance in Escherichia coli. Appl Environ Microbiol 64, 5042-5045.

Gupta, A., Matsui, K., Lo, J.-F. \& Silver, S. (1999). Molecular basis for resistance to silver cations in Salmonella. Nature Med $\mathbf{5}$, 183-188.

Hendry, A. T. \& Stewart, I. O. (1979). Silver-resistant Enterobacteriaceae from hospital patients. Can J Microbiol 25, 915-921.

Hoch, J. A. \& Silhavy, T. J. (editors) (1995). Two-Component Signal Transduction. Washington, DC: American Society for Microbiology.

Li, X. Z., Nikaido, H. \& Williams, K. E. (1997). Silver-resistant mutants of Escherichia coli display active efflux of $\mathrm{Ag}^{+}$and are deficient in porins. J Bacteriol 179, 6127-6132.

Liu, H. H. (1999). Antibiotic resistance in bacteria. A current and future problem. Adv Exp Med Biol 455, 387-396.

Lorscheider, F. L., Vimy, M. J. \& Summers, A. O. (1995). Mercury exposure from 'silver' tooth fillings: emerging evidence questions a traditional dental paradigm. FASEB J 9, 504-508.

Lygre, G. B., Hol, P. J., Eide, R., Isrenn, R. \& Gjerdet, N. R. (1999). Mercury and silver in saliva from subjects with symptoms selfrelated to amalgam fillings. Clin Oral Investig 3, 216-218.

McHugh, S. L., Moellering, R. C., Hopkins, C. C. \& Swartz, M. N. (1975). Salmonella typhimurium resistant to silver nitrate, chloramphenicol, and ampicillin. Lancet i, 235-240.

Modak, S. M. \& Fox, C. R., Jr (1973). Binding of silver sulfadiazine to the cellular components of Pseudomonas aeruginosa. Biochem Pharmacol 22, 2391-2404.

Nies, D. H. (1995). The cobalt, zinc, and cadmium efflux system CzcABC from Alcaligenes eutrophus functions as a cation-proton antiporter in Escherichia coli. J Bacteriol 177, 2707-2712.

Perna, N. T., Plunkett, G., III, Burland, V. \& 25 other authors (2001). Genome sequence of enterohemorrhagic Escherichia coli O157: H7. Nature 409, 529-533.

Pruitt, B. A., Jr, McManus, A. T., Kim, S. H. \& Goodwin, C. W. (1998). Burn wound infections: current status. World J Surg 22, $135-145$. 
Rensing, C., Ghosh, M. \& Rosen, B. P. (1999). Families of softmetal-ion-transporting ATPases. J Bacteriol 181, 5891-5897.

Rensing, C., Fan, B., Sharma, R., Mitra, B. \& Rosen, B. P. (2000). CopA: An Escherichia coli $\mathrm{Cu}(\mathrm{I})$-translocating P-type ATPase. Proc Natl Acad Sci US A 97, 652-656.

Russell, A. D. \& Hugo, W. B. (1994). Antimicrobial activity and action of silver. Prog Med Chem 31, 351-370.

Saier, M. H., Jr, Tam, R., Reizer, A. \& Reizer, J. (1994). Two novel families of bacterial membrane proteins concerned with nodulation, cell division and transport. Mol Microbiol 11, 841-847.

Salyers, A. A. \& Amabile-Cuevas, C. F. (1997). Why are antibiotic resistance genes so resistant to elimination? Antimicrob Agents Chemother 41, 2321-2325.

Shigekawa, K. \& Dower, W. J. (1988). Electroporation of eukaryotes and prokaryotes: a general approach to the introduction of macromolecules into cells. BioTechniques $\mathbf{6}$, 742-751.

Silver, S. (1998). Genes for all metals - a bacterial view of the Periodic Table. J Indust Microbiol Biotechnol 20, 1-12.
Silver, S. \& Phung, L. T. (1996). Bacterial heavy metal resistance: new surprises. Annu Rev Microbiol 50, 753-789.

Silver, S., Gupta, A., Matsui, K. \& Lo, J.-F. (1999a). Resistance to $\mathrm{Ag}(\mathrm{I})$ cations in bacteria: environments, genes and proteins. Metal-Based Drugs 6, 315-320.

Silver, S., Lo, J.-F. \& Gupta, A. (1999b). Silver cations as an antimicrobial agent: clinical uses and bacterial resistance. Alliance Prudent Use Antibiot Newsl 17, 1-3.

Silver, S., Novick, R. \& Gupta, A. (2000). Mechanism of resistance to heavy metals and quaternary amines. In Gram-Positive Pathogens, pp. 647-659. Edited by V. A. Fischetti, R. P. Novick, J. J. Ferretti, D. A. Portnoy \& J. Rood. Washington, DC: American Society for Microbiology.

Solioz, M. \& Odermatt, A. (1995). Copper and silver transport by CopB-ATPase in membrane vesicles of Enterococcus hirae. J Biol Chem 270, 9217-9221.

Received 2 April 2001; revised 20 June 2001; accepted 20 August 2001. 